\title{
Análise sobre a concepção de vida nua: por uma política vital
}

\section{Enock da Silva Peixoto ${ }^{1}$}

1 Doutorando em Filosofia pela UERJ e UFRJ. Mestre em Educação pela UNIRIO. Docente na Secretaria de Educação da Bahia, Brasil. E-mail: enock-peixoto@hotmail.com Orcid: http://orcid.org/0000-0003-4687-2018

RESUMO: O texto a seguir é uma análise sobre a concepção de vida nua presente no livro Homo Sacer, o poder soberano e a vida nua I do filósofo italiano Giorgio Agamben. Salientamos que o tema não se reduz a este livro sendo possível um entendimento mais preciso sobre o mesmo em obras posteriores, mas como se trata de um estudo introdutório, nos ateremos na obra supracitada conscientes de que o termo central "poder soberano e vida nua" não se restringe a este momento da construção filosófica de Agamben. O trabalho será desenvolvido em dois momentos, primeiro apresentaremos sinteticamente o conceito de vida nua para o pensador romano, considerando a sua leitura do termo a partir de Walter Benjamim. Destacaremos como o pensador italiano, parte do filósofo alemão, para desenvolver a concepção de homo sacer, situação na qual, o estado de excę̧ão é sempre constante na modernidade; perpassaremos os seus estudos sobre o tema proposto, desde a Antiguidade até a sua expressão na política moderna. No segundo passo, vislumbramos mostrar como é possível extrair do estudo sobre a vida nua, uma possibilidade de repensar a função da política na vida atual. Embora já sejam de conhecimento geral, delinearemos algumas situações contemporâneas que são reflexo de uma política sustentada na concepção do homem como sacer, como corpos matáveis e sacrificáveis. Destacaremos a necessidade de reaproximação entre política e vida, considerando que o direito e política só têm valor se existirem para dignificar e qualificar a existência humana, que por si só, sem as interferências controladoras e ensimesmadas da vida pública institucional, já é bastante complexa de ser vivida.

Palavras chave: política; vida nua; homo sacer

ABSTRACT: The following text is an analysis of the conception of bare life present in the book: Homo Sacer: sovereign power and bare life of the Italian philosopher Giorgio Agamben. We emphasize that the subject is not reduced to this book and a more precise understanding of it is possible in later works, but as it is an introductory study, we focus on the work mentioned above, aware that the central term "sovereign power and naked life "Is not restricted to this moment of Agamben's philosophical construction. It will be developed in two moments: first we will present synthetically the concept of bare life for the roman thinker, starting from his reading of the term from Walter Benjamim. We will point out how the Italian thinker starts from the German philosopher to develop his conception of homo sacer, for whom the state of exception is always constant in modernity. We will go from his studies from antiquity to his expression in modern politics. We will point out how it is possible to extract from the study of this term a possibility of rethinking the function of politics in our present life. In the second step, we envisage to show how it is possible to extract from the study of this term a possibility of rethinking the function of politics in our present life. Although they are generally known, we will delineate some contemporary situations that are a reflection of a sustained policy in the conception of man as sacer, as killable and sacrificial bodies. We will emphasize the need for a rapprochement between politics and life, considering that law and politics only have value if they exist to dignify and qualify human existence, which alone, without the controlling and enshrouded interference of institutional public life, is already quite complex be lived.

Keywords: politics; bare life; homo sacer 


\section{A concepção de "vida nua"}

O estudo sobre a vida nua em Giorgio Agamben perpassa a interpretação que o filósofo italiano elabora do termo, a partir de sua gênese na filosofia de Walter Benjamim. Trata-se da existência desprovida de direitos ou da forma como a política se apropria diretamente da vida dos indivíduos. Remete ao estudo que ambos os filósofos fazem sobre o estado de exceção. Vida nua se encontra dentro da delimitação da vida à política, ou seja, submete as forças vitais humanas, o corpo físico e social dos indivíduos à "égide” do controle jurídico-político estatal.

No livro Homo sacer I, Agamben alude a Benjamim e cita o filósofo alemão sobre o nexo entre violência e direito: "remonta a culpabilidade da vida nua natural, a qual entrega o vivente, inocente e infeliz, a pena, que expia (sübnt) a sua culpa e purifica (entsübnt) também o culpado, não, porém de uma culpa, e sim do direito" (BENJAMIN, 1989, p. 153, apud, AGAMBEN, 2007, p. 73). Benjamin não explicita de forma clara o que é a vida nua e é este o trabalho que Agamben se propõe a realizar. É possível, entretanto, inferir das afirmações benjaminianas que se trata de uma vida que, na modernidade, perdeu a sua especificidade. Está vazia daqueles atributos que carregara no decorrer da história. A vida nua se tornou política no ocidente, ela é regra sempre vigente, e desse modo, o conceito está diretamente associado ao de estado de excȩão.

O propósito deste texto não é debater as questões específicas relativas ao conceito de estado de exceção, cerne fundamental da filosofia de Agamben, mas é necessário ressaltar o seu contraste com idéia de poder soberano. Walter Benjamin diverge da concepção de soberania defendida pelo teórico Carl Schmitt, jurista alemão engajado nas causas nacional-socialistas. Schmitt "debate" com Benjamim sobre o estado de excȩ̧ão e suas análises são fontes da discussão do livro de mesmo nome, de Giorgio Agamben. Na obra Teologia política Schmitt (2006) sustenta a sua famosa frase: "Soberano é o quem decide sobre a exceção". O soberano tem poderes quase que absolutos, em momentos de tensão estremada seria legitimo suspender a constituição, sendo este um evento necessário para a manutenção da norma, neste contexto, a anormalidade funda a regra. O soberano tem o poder de decisão sobre a vigência do estado de direito, algo que Benjamin destacará como a regra que define o Estado (2012. p. 245):

A tradição dos oprimidos nos ensina que o "estado de exceção" ("Ausnahmezustand") em que vivemos é regra. Precisamos construir um conceito de história que corresponda a esse ensinamento. Perceberemos, assim, que nossa tarefa é originar um verdadeiro estado de exceção; e com isso nossa posição ficará melhor na luta contra o fascismo. Este se beneficia da circunstância de que seus adversários o enfrentam em nome do progresso, considerado como uma norma histórica. - O assombro com o fato de que os episódios que vivemos no século XX “ainda” sejam possíveis, não é um assombro filosófico. Ele não gera nenhum conhecimento, a não ser o conhecimento de que a concepção de história em que se origina é insustentável.

Segundo Schmitt, para estabelecer a normalidade, a segurança social, é necessário que o soberano possa decidir pela exceção ou sanar com a mesma, sendo essa uma estratégia para salvaguardar o próprio Estado, para Benjamin, entretanto, o estado de exceção é um perigo para a vida, pois a torna vulnerável, "como violência pura - uma existência fora do direito" (2004, p. 94).

Vimos, de forma sintética, que a concepção de vida nua é originaria em Benjamin, mas Agamben faz uma leitura própria do conceito, pois parte da sua presença sempre constante em nossa cultura, desde as suas origens no direito romano, perpassando pela experiência moderna que atravessa, necessariamente, vidas humanas desprovidas de direito. Será esta relação que passaremos a destacar a seguir. 


\section{Agamben e o homem sacro}

Conforme comenta Agamben (2007), o homem sacro, que no direito romano, corresponde ao indivíduo que havia cometido um crime bárbaro, não podia ser morto com base nos ritos sacrificais religiosos, e por isso, estava fora da decisão jurídica tanto civil como religiosa; mas se alguém o matasse, o homicida não seria passível de punição. Imaginemos o tamanho da vulnerabilidade de uma pessoa nesta situação, que tem a sua vida totalmente desprovida da defesa da lei e exposta à virulência de quem desejasse extirpá-la! Para Edgardo Castro (2012, p. 44):

A vida do homo sacer, a vida nua, é a vida da qual se pode dispor sem necessidade de celebrar sacrifícios e sem cometer homicídio. Nenhuma das explicações oferecidas a respeito logrou dar razão do duplo caráter do homo sacer : insacrificável, porém exposto à morte. E tampouco, assinala também com ênfase Agamben, ela pode ser explicada a partir do mitologema da ambiguidade do termo "sacer" (sagrado). A sacralidade da vida nua configura-se, antes, não a partir de uma ambiguidade, mas de uma dupla exceção que a exclui, incluindo-a, tanto do direito divino, e por isso não pode ser objeto de sacrifício, como o direito dos homens, e por isso se pode dispor dela sem cometer homicídio. Não é a ambiguidade do sagrado o que a explica, mas seu isomorfismo com a relação de exclusão inclusiva do dispositivo soberano.

Trata-se de uma vida insacrificável, mas ao mesmo tempo matável, vida nua em todos os sentidos, pois totalmente desprovida da proteção dos deuses e dos homens. É essa imagem do homem desnudo totalmente de direitos que move Agamben a analisar a política e o direito na sociedade moderna. Em Homo Sacer I, o filósofo destaca a pretensão de dar continuidade as pesquisas de Michel Foucault sobre a biopolítica, ou seja, o modo como a modernidade aproximou a política da vida; mas não de maneira propositiva, com a intencionalidade de edificar a existência, mas como uma forma de dominá-la. O filósofo italiano analisará os campos de concentração nazista como uma prática que evidenciou este vínculo tênue entre o poder soberano e a biopolítica, mas, diferente de Foucault, que restringe esta experiência à era Moderna. Agamben a estende para a Antiguidade, para ele, a relação de soberania e biopoder sempre existiram na estrutura jurídica no Ocidente.

Agamben considera estranho que os dois pensadores que com mais cuidado abordaram o problema político contemporâneo, Foucault com sua análise sobre o biopoder e Hannah Arendt, sobre os campos de concentração e o totalitarismo do século passado, não tenham convergido as suas teses. Então, ele se propõe a destacar que "o conceito de "vida nua" ou "vida sacra" é o foco através do qual [procurará] fazer convergir os seus pontos de vista" (AGAMBEN, 2007, p.126).

Notemos que procurar convergir às teses não confrontadas de Foucault e Arendt sobre a biopolítica e a ação sobre a vida nos regimes totalitários pautam a concepção de vida nua ou vida sacra para o filósofo. Ora, isto significa como já acenamos anteriormente, que o propósito de Agamben fora destacar a proximidade da biopolítica com a noção de soberania, sendo estas duas últimas, geradoras de uma estrutura jurídica que atua sobre a vida humana com o intento de torná-la puramente política.

Após essas análises é necessário destacar como Agamben interpreta os termos bios e qoé e a sua correspondência com o conceito de vida nua. Iniciemos pela distinção entre essas palavras gregas. A zoé se refere à vida natural, aquela que recebemos da natureza, trata-se do simples viver, é a nossa proximidade com os demais seres vivos. Bíos trata de uma vida específica dos humanos, própria daqueles que são capazes de utilizar a razão, o logos, e qualificar a existência politicamente. Mas conforme Agamben, a simples 
vida natural é excluída da pólis propriamente dita. Esta era confinada apenas como vida reprodutiva restrita ao âmbito do ổkos (AGAMBEN, 2007). Ocorre o que Agamben define como uma exclusão inclusiva, pois a família não faz parte da vida pública, mas existe tendo em vista a existência na pólis, ou seja, a bios e a zoé se incluem e excluem simultaneamente. A vida política no ocidente segundo Agamben (2007) nasce de uma exclusão e ao mesmo tempo é implicação da vida nua. Compreender o porquê desta inclusão através de uma exclusão torna-se um ponto primordial para compreender a política ocidental. Conforme comenta André Duarte (2010, p. 84).

O que interessa a Agamben, quando anuncia que o campo de concentração se torna paradigma definitivo da política, é entender justamente como esta produz uma vida que pode ser liquidada sem que, no entanto, se cometa assassinato. Para entender esse fenômeno, Giorgio Agamben vai ao direito romano, de onde busca uma figura que pode lhe servir de paradigma para começar a dar visibilidade ao problema. Eis o homo sacer: indivíduo que na sociedade romana perdia a proteção da lei, e, portanto, relacionava-se com ela pela forma da exclusão, mas que também não poderia ser morto em sacrifício, de modo que também se relacionava com a ordem religiosa pela forma da exclusão [...].

$\mathrm{Na}$ sociedade moderna, entretanto, a vida natural, a bíos e a zoé entram na política e a relação de uma exclusão inclusiva deixa de existir. Como afirma Agamben, bios e zoé entram numa zona de indistinção. Desse modo, o centro da análise política agambeniana é a vida nua, sendo esta a protagonista do livro: "Protagonista deste livro e a vida nua, isto é, a vida matável e insacrificável do homo sacer, cuja função essencial na política moderna pretendemos reivindicar" (AGAMBEN, 2007, p. 16). Essa figura paradoxal, o homo sacer, uma vida irrelevante que tanto do ponto de vista religioso, como jurídico, era ao mesmo tempo normalizada e fora da norma: "no homo sacer [...] nos encontramos diante de uma vida residual e irredutível, que deve ser excluída e exposta à morte como tal, sem que nenhum rito e nenhum sacrifício possam resgatá-la” (AGAMBEM, 2007, p. 107).

Neste estudo sobre o homo sacer no mundo Antigo, Agamben demonstra a forma como o direito se refere à vida. Não se trata de um meio de defesa da mesma, como ocorrera na modernidade, com as Declarações dos Direitos do Homem, mas apenas como um distanciamento do poder civil e divino, conforme o filósofo:

[...] uma vida que, excepcionando-se em uma dupla exclusão do contexto real das formas de vida, sejam profanas ou religiosas, é definida apenas pelo seu ser em intima simbiose com a morte, sem porém pertencer ainda ao mundo dos defuntos. E é na figura desta 'vida sacra' que algo como uma vida nua faz a sua aparição no mundo ocidental (AGAMBEN, 2007, p. 107).

Se o soberano é sacro diante dos homens, o homo sacer é vulnerável e qualquer um, diante dele, pode agir como soberano: "soberano é aquele em relação ao qual todos os homens são potencialmente homines sacri e homo sacer é aquele em relação ao qual todos os homens agem como soberanos" (AGEMBEN, 2007, p. 92); o direito de viver ou morrer para o sacer era extremamente iminente.

Agamben analisa também, como uma expressão desse poder sacer, a posição do pater famílias sobre o filho varão. Esse é também um poder de vida e de morte. Era uma exceção, pois o filho tinha que, em situações extremadas, pagar com a vida a sua participação na esfera pública, os filhos deviam saldar "sua participação na vida política com uma incondicional sujeição a um poder de morte, e [...] pudesse entrar na cidade somente na dupla exceção da matabilidade e da insacrificabilidade" (AGAMBEN, 2007, p.98). O varão tinha os seus direitos limitados enquanto o pai estivesse vivo e por isso, sua vida estava exposta a 
possibilidade de ser eliminada pelo pai, a vida do filho não era sua. Agamben acena que a inclusão na vida política ocorria de forma violenta, como uma exposição truculenta sobre a vida nua, como ocorre nesta relação pai-filho no direito romano.

Mas a vida nua que Agamben analisa se confunde com a bios ou zoẹ? Ela é um significante flutuante, pois está exporta tanto do ponto de vista civil como do religioso, é vida sem proteção, sem que tenha sobre ela o "olhar cuidadoso da lei”, mas mesmo assim, não foge do seu controle, ela, curiosamente é destituída de direitos pelo próprio direito. Sustenta Agamben, "nem bíos político, nem zoé natural, a vida sacra é a zona de indistinção na qual, implicando-se e excluindo-se um ao outro, estes se constituem mutuamente" (AGAMBEN, 2007, p.98). A vida nua é a zoé entregue ao poder soberano, trata-se da vida despida de direitos.

Para Agambem, desde a Antiguidade, a vida nua está associada ao poder soberano, trata-se da existência daqueles sujeitos sociais que estão circunscritos pela égide da lei, mas que embora excluídos sejam destacados pela própria norma que os segrega. O filósofo apresenta outras experiências que evidenciam uma existência sob os limites da vida nua, destaquemos, a sua referência ao lobo do direito primitivo alemão e a sua exclusão da comunidade:

A antiguidade germânica e escandinava nos oferecem, além de qualquer dúvida, um irmão do homo sacer no bandido e no fora-da-lei (...), o lobo, e, no sentido religioso, o lobo sagrado, (...). Aquilo que é considerado uma impossibilidade para a antiguidade romana - a morte do proscrito fora de um juízo e do direito - foi uma realidade incontestável na antiguidade germânica. (JHERING, 1886, p. 282. apud, AGAMBEN, 2007, p. 111).

Este é um texto do jurista alemão Caspar Rudolf Von Jhering que introduz o capítulo de Homo sacer I que aborda sobre o bando e o lobo. Trata-se da figura do bandido, do homem lobo, aquele que por causa dos seus crimes fora banido da comunidade, e desse modo, sua vida podia ser eliminada. O lobisomem assinala Agamben, é definido como homem-lobo e não somente como lobo. Sua vida de bandido se assemelha a de um homem sacro e não está indiferente ao direito, mas funciona como indiferença entre animal e homem, ele habita o mundo do homem e da fera sem pertencer a nenhum deles (AGAMBEN, 2007). A soberania atua exatamente dentro deste limiar no qual a vida torna-se domínio exclusivo de outrem.

As figuras do criminoso romano; do filho "sem vida social", até que o pai morresse e a do bandido como lobo abandonado foram as que destacamos para delinear como Agamben apresenta a concepção de vida nua. Essa vida sem direitos, vida controlada, vida que é a base para elucidar um estilo de existência no qual o homo sacer é o personagem que demarca a cena do existir coletivo e individual predominante em nossa cultura. Avaliaremos a seguir, como o pensador italiano em estudo situa a concepção de vida nua no mundo moderno.

\section{A vida nua como fundamento do Estado Moderno}

Analisando as bases da política moderna, fundada na perspectiva da soberania, Agamben estuda a concepção de estado de Thomas Hobbes, da qual se conclui que não é verdadeira a idéia de que a soberania traz liberdade, primando pelo contrato social os direitos do cidadão. Noção contrastada com a frase destacada: "autenticamente política é somente a vida nua" (AGAMBEN, 2007, p. 113). E continua o filósofo italiano comentando sobre um dos precursores do pensamento sobre a soberania na modernidade Hobbes - para quem, o fundamento do poder soberano deve ser buscado não no direito natural dos súdi- 
tos, mas no direito do soberano de fazer qualquer coisa em relação a qualquer um, ou seja, o seu direito soberano de punir:

A violência soberana não é, na verdade, fundada sabre um pacto, mas sabre a inclusão exclusiva da vida nua no Estado. E, como o referente primeiro e imediato do poder soberano é, neste sentido, aquela vida mutável e insacrificável que tem no homo sacer o seu paradigma, assim também, na pessoa do soberano, o lobisomem, o homem lobo do homem, habita estavelmente na cidade (AGAMBEM, 2007, p. 113).

A fundação do Estado Moderno não tem na verdade como premissa o acordo entre os cidadãos para que todos decidam a melhor forma de viver, mas se estabelece sobre uma perspectiva da vida nua, como o estado de natureza é na verdade um estado de exceção (AGAMBEN, 2007, p. 115). A vida nua não é mais incluída ou excluída, mas ela é o desígnio direto da estrutura estatal moderna, ela é legalmente "politizada". Sustenta este argumento o que assevera Agamben: "o primeiro registro da vida nua como novo sujeito político já está implícito no documento que é unanimemente colocado à base da democracia moderna: o writ de Habeas corpus de 1769" (AGAMBEN, 2007, p.129). "Tome o seu corpo", o direito de ir e vir, de estar imbuído do devido processo legal, parece ser algo propositivo, importante para as liberdades individuais e a delimitação do poder sobre os sujeitos. Mas por qual razão Agamben coloca esta categoria jurídica, base de nossa democracia, como primeiro "registro da vida nua"? Trata-se de um corpo que é dominado pelo poder jurídico, ele tem que necessariamente se apresentar a juízo, não se trata de uma opção, é uma obrigação. O corpo do delituoso é de domínio estatal; "a nascente democracia européia colocava no centro de sua luta com o absolutismo não bíos, a vida qualificada de cidadão, mas qoé, a vida nua em seu anonimato, apanhada como tal, no bando soberano" (AGAMBEN, 2007, p. 130).

O simples nascimento, ou seja, a caracterização mais próxima da vida biológica, já possibilita ao indivíduo a relação intrínseca com a política: "Um simples exame do texto da declaração de 1789 mostra [...] justamente a vida nua natural, ou seja, o puro fato do nascimento, a apresentar-se aqui como fonte e portador do direito" (AGAMBEN, 2007, p.134). Salientemos, no entanto, que a tese dos direitos inalienáveis na atualidade encontra diversos oponentes, dentre eles os filósofos já citados Hannah Arendt e Michel Foucault. Para Arendt, segundo interpretação de André Duarte, a filosofia contratualista e as Declarações de 1776 e 1778, respectivamente, a da Virginia, preparatória para a declaração estadudinense e a Declaração dos Direitos do Homem e do Cidadão; ambas foram virtuosas ao fazer do homem cidadão e dos direitos serem considerados inalienáveis, mas, esta fundamentação dos direitos na concepção de natureza humana foi desafiada por aqueles homens sem lugar na sociedade e na política, como, os apátridas e as minorias (DUARTE,2000, p.43) . O raciocínio, no entanto é que ainda não encontramos um modo dos direitos atingirem efetivamente a todos, logo, sabemos que o fato de nascer não garante direitos para milhões de indivíduos e deste modo, está longe de estar pacificada a questão dos direitos inalienáveis, pois a realidade a contesta constantemente. Mas, retomando a análise de Agamben, ocorre uma aproximação entre o ato de nascer e politização da vida, ou seja, a zoé já emerge predeterminada ao soberano, o indivíduo é imediatamente associado ao direito pelo puro nascimento. Mas embora essa redefinição da vida nua, possivelmente nascesse com boas intenções, como aquela de defender a vida e não torná-la vulnerável, inclusive em relação aos soberanos, há nela, para Agamben, uma cesura:

os Estados-nação operam um maciço reinvestimento da vida natural, discriminando em seu interior uma vida por assim dizer autêntica e uma vida nua privada de todo valor político [...] por outro, os di- 
reitos do homem, que faziam sentido apenas como pressuposto dos direitos do cidadão, separam-se progressivamente destes e são utilizados fora do contexto da cidadania, com o suposto fim de representar e proteger uma vida nua que vem a encontrar-se, em proporção crescente, expulsa as margens dos Estados-nação, para ser então posteriormente recodificada em uma nova identidade nacional (AGAMBEN 2007, p.139).

O nazismo e o fascismo são exemplos objetivos e claros dessa "redefinição entre o homem e o cidadão". O que ocorre de perigoso nessa relação da vida nua entregue ao poder do estado? "na biopolítica moderna, soberano é aquele que decide sobre o valor ou sobre o desvalor da vida enquanto tal" (AGAMBEN, 2007, p.169). Neste caso, vida e política se confundem, sendo a primeira uma questão de Estado. Se na situação de exceção na Antiguidade a vida nua estava sobre o controle e decisão do soberano, na vida moderna, não há aquela distinção entre bios e qóe, mas a vida pode ser de forma direta, desde a sua origem, um instrumento legal. Não há mais excepcionalidade na qual o soberano deve decidir sobre ela, mas ela é por todo o tempo uma questão de norma, ela já nasce judicializada. O perigo é que tal vida nua poderá ser desprovida absolutamente de direitos, uma vida totalmente submetida ao poder do Estado, como ocorrera nas prisões nazistas. Segundo Duarte (2010, p. 84):

Para além de sua dimensão propriamente jurídica e carcerária, tais prisões constituem um espaço ambíguo que comporta a inclusão do preso no sistema formal, mas também sua total exclusão, não apenas nas situações em que o detento é sistematicamente torturado, mas também naquelas em que permanece preso após ter cumprido sua pena, e, sobretudo, naqueles momentos de conflito deflagrado: em todas essas ocasiões mostra-se que o detento não é considerado como cidadão portador de direitos temporariamente limitados, mas, sim, como encarnação excessiva - há sempre um excedente de prisioneiros nessas prisões - da vida que não merece viver e que pode ser descartada e assassinada sem que se cometa delito.

Os campos de extermínio nazistas possibilitaram um controle brutal sobre a vida, funcionavam como uma maquinaria eficiente que se denominava justificável, ordenação jurídica que selecionava a vida digna e a indigna de ser vivida. Além disso, a ciência e a medicina também emergem nesse contexto de domínio sobre a vida: Agamben, em Homo Sacer I, debate com as teses de Karl Binding, especialista de direito penal e Alfred Hoche, professor de medicina. A eutanásia é o centro da questão. Afirma Agamben: "A estrutura biopolítica fundamental da modernidade - a decisão sobre o valor (ou sobre o desvalor) da vida como tal - encontra, então, a sua primeira articulação jurídica em um bem-intencionado pamphlet a favor da eutanásia” (2007, p. 144). Trata-se do governo sobre o corpo, a decisão sobre aquelas vidas, que por não poderem mais subsistir de um modo considerado adequado, podem ser eliminadas de forma legal, sem que haja algum tipo de punição a tal ato. "A nova categoria jurídica de 'vida sem valor' (ou 'indigna de ser vivida') corresponde ponto por ponto, ainda que em uma direção pelo menos aparentemente diversa, à vida nua do homo sacer" (AGAMBEN, 2007, p. 146). A preocupação de Agamben não é com as complexas questões que a eutanásia desperta ainda hoje, mas o poder de decisão sobre os humanos sacros, aqueles que devem ou não morrer.

O regime nazista fora a expressão mais tênue dessa violência sobre os corpos. A agressão aos VP (cobaias humanas), ou seja, pessoas que foram utilizadas para se fazer com elas pesquisas científicas, exemplifica esta vulnerabilidade do sacer contemporâneo. Este tipo de experiência foi sofrida por integrantes dos campos de concentração; aviadores alemães considerados “delinquentes de profissão" e diversos tipos de prisioneiros condenados. Em relação aos campos, afirma o filósofo italiano: 
Justamente porque privado de quase todos os direitos e expectativas que costumamos atribuir à existência humana e, todavia, biologicamente ainda vivos, eles vinham a situar-se em uma zona-limite entre a vida e a morte, entre o interno e o externo, na qual não eram mais que vida nua. Condenados à morte e habitantes do campo são, portanto, de algum modo inconscientemente assemelhados a homines sacri, a uma vida que pode ser morta sem que se cometa homicídio (AGAMBEN, 2007, p.166).

Juristas chegaram ao absurdo de fazerem condenados assinarem "livremente" o direito de participar de tais experiências, ou seja, uma forma de estabelecer legalidade a uma possível morte violenta, isentando o Estado de responsabilidades. Não é mais somente o soberano que penetra neste universo da vida nua, de decisão unilateral sobre a vida e a morte, mas a ciência também passa a integrar esse processo: "no horizonte biopolítico que caracteriza a modernidade, o médico e o cientista movem-se naquela terra de ninguém onde, outrora, somente o soberano podia penetrar" (AGAMBEN, 2007, p.166). Trata-se de um corpo que é matável e insacrificavel, assim como o homo sacer porque não depende da análise penal. O mesmo ocorre com o indivíduo com morte cerebral, na sala de reanimação ele é como um objeto da decisão médica:

A sala de reanimação onde flutuam entre a vida e a morte o néomort, o além-comatoso e o faux vivante delimita um espaço de exceção no qual surge, em estado puro, uma vida nua pela primeira vez integralmente controlada pelo homem e pela sua tecnologia. E visto que se trata não de um corpo natural, mas de uma extrema encarnação do homo sacer (o comatoso pôde ser definido como 'um ser intermediário entre o homem e o animal') a aposta em jogo e mais uma vez, a definição de uma vida que pode ser morta sem que se cometa homicídio (AGAMBEN, 2007, p.171).

Eis mais um exemplo do domínio sobre a vida na era moderna que tornou cada vez mais abrangente a ação sobre o sacer, este, além de ser um problema político-jurídico, é também uma questão de tecnologia médico-científica. O agravante de toda esta presença da zoé que se confundiu com a bíos na sociedade moderna é que essa experiência ultrapassou os campos e entrou como elemento constitutivo da vida social. Agamben explicita três teses, no final do livro em análise, que demonstram essa afirmação.

Três teses emergiram como conclusões provisórias, no curso desta pesquisa: 1) A relação política originária é o bando (o estado de exceção como zona de indistinção entre externo e interno, exclusão e inclusão); 2) o rendimento fundamental do poder soberano e a produção da vida nua como elemento político original e como limiar de articulação entre natureza e cultura, zoe e bios; 3) o campo, e não a cidade, é hoje o paradigma biopolitico do Ocidente (AGAMBEN, 2007, p. 187).

Destaquemos o comentário que o filósofo elabora sobre a terceira dessas teses:

como "uma sombra sinistra se abre os modelos através das quais as ciências humanas, a sociologia, a urbanística, a arquitetura procuram hoje pensar e organizar o espaço público das cidades do mundo, sem ter uma clara consciência de que em seu centro (ainda que transformada e tornada aparentemente mais humana) está ainda aquela vida nua que definia a biopolitica dos grandes Estados totalitários do Novecentos" (AGAMBEN, 2007, p. 187).

Para o filósofo, portanto, não há como repensar o paradigma político moderno que nos assola ainda hoje, sem considerar as suas bases estruturais. De que o estado de exceção é preeminente em nossa cultura; de que há uma relação entre bios e qoé na vida contemporânea e é no campo que devemos buscar as leituras para interpretar e reorganizar o espaço público. "Pode-se dizer [...] que poderá ser descortinada uma rota 
para pensar a politização da vida operada no horizonte da modernidade jurídico-política ocidental, conectando-nos [...] com a redução da política à biopolítica no ocidente” (BARBOSA, 2009, p. 113). Logo, a tese de Agamben é de que repensar a política necessariamente passa pela sua organização originária, que já nasceu sacer, cujas características se pautam sobre a exceção, sobre a exclusão de vidas humanas, algo que as humanidades, as ciências sociais e até a organização da polis moderna não fugiram de seus efeitos.

Se a vida contemporânea tem por substrato a vida nua, torna-se necessário repensar a sua eficiência como modo de edificação de nossa curta existência. Uma política vital, ou seja, uma organização social que privilegia a dignidade humana de forma objetiva, sem que a decisão sobre a vida-morte dos indivíduos não seja banalizada é algo ainda a se construir, certamente, sobre outras bases.

\section{Reflexões sobre a vida nua na atualidade}

Concordemos ou não com as teses de Agamben de que vivemos em um estado de excȩão é notória, na realidade contemporânea, vidas que são matáveis, homens, mulheres, crianças que são sacer. A vida sacra, que deveria estar protegida pelos direitos humanos, se tornou para grande parte dos viventes atuais, necessariamente, vida nua. A análise de Barbosa assevera esta reflexão:

[...] a sacralidade da vida que se tenta opor, a todo custo, contra a sua cotidiana suspensão (seja em um campo de concentração do séc. XX, em um "não-lugar" biopolítico como Guantánamo ou mesmo na cotidianas mortes em acidentes rodoviários) - fulcrada de forma solene na bandeira dos inalienáveis direitos humanos - nada mais representa que a sacralidade-matabilidade modelada nos termos da figura do homo sacer (BARBOSA, 2009, p. 13).

Além da referência acima sobre as diversas mortes no trânsito e dos prisioneiros de Guantánamo, como imagens da vida nua atual, podemos estender essa concepção para uma lista quase sem fim, em vários lugares do planeta nos quais a existência é tratada como indigna de ser vivida: podemos apontar os diversos navios de refugiados africanos afundados na costa do mediterrâneo; os refugiados sírios espalhados pelo mundo; o perigo de um palestino adentrar em território judeu e vice-versa; a complexa situação dos nossos vizinhos da Venezuela; o tráfico de crianças, de mulheres para a prostituição, de órgãos humanos; situações nas quais vidas são açoitadas sobre o chicote de um poder desumano e dominador. Vítimas de um mito de que realmente existe estado de direito:

Essa violência inerente e oculta do direito é o que legitima a injustiça em que vivemos e por vezes se torna visível em episódios como os campos de concentração, aeroportos que rejeitam refugiados, favelas em que vida está exposta à morte, zonas rurais dominadas por coronéis. Nesses locais a vida está nua, ou seja, totalmente exposta, totalmente submissa a um poder que pode a descartar livremente. Então a conclusão dessa primeira parte é: o estado de exceção não é "exceção", mas a regra sobre o qual o estado de direito se ergue como uma espécie de mito que encobre as relações de poder reais que existem (PINTO NETO, 2010, p. 143).

Passando para os nossos problemas internos, somente neste ano de 2019, inúmeros índios foram assassinados por defenderem as suas terras e sua forma específica de se relacionar com o mundo, o mesmo vem ocorrendo com comunidades quilombolas. No Estado do Rio de Janeiro, predominantemente em comunidades pobres, várias pessoas inocentes e "não inocentes" estão sendo sistematicamente mortas, algo que não deveria ocorrer do ponto de vista legal, considerando que vivemos em um suposto Estado 
democrático. Vale destacar a vida de inúmeros policiais que no exercício de sua função vem tendo as suas existências ceifadas de forma brutal, assim como os criminosos, ambos estão do mesmo lado quando a questão é o "direito de morrer". Todos esses são exemplos de vidas que são matáveis e em muitos casos, sem causar nenhum peso no "inconsciente coletivo" da sociedade. Para muitas pessoas, certas vidas são menos importantes que outras; o que demonstra que a consciência de vidas nuas se tornou disseminada na textura social.

No inicio do ano de 2017 foi lançado pelo Instituto de Pesquisa Econômica Aplicada (Ipea) e o pelo Fórum Brasileiro de Segurança Pública o "Atlas da violência" ( Cf. Instituto Brasileiro de Pesquisas Aplicadas (IPEA), 2017). Esse revela que "homens, jovens, negros e de baixa escolaridade são as principais vítimas de mortes violentas no País. A população negra corresponde a maioria $(78,9 \%)$ dos $10 \%$ dos indivíduos com mais chances de serem vítimas de homicídios". E continua o estudo: "Atualmente, de cada 100 pessoas assassinadas no Brasil, 71 são negras [...] os negros possuem chances 23,5\% maiores de serem assassinados em relação a brasileiros de outras raças" (Ibidem, 2017). O estudo também aponta para a situação caótica da violência contra jovens e mulheres: "Em 2015, cerca de 385 mulheres foram assassinadas por dia. A porcentagem de homicídio de mulheres cresceu 7,5\% entre 2005 e 2015, em todo o País". Ora, essas categorias de pessoas, de vidas nuas, que pela sua raça ou gênero, opção sexual, situação socioeconômica, sofrem como se estivessem dissociadas do grupo social e da proteção legal.

Mas a pergunta fundamental é: quem é o soberano que arroga para si, atualmente, o direito de se dispor de todas essas vidas? Endentemos que uma entrevista de Agamben na qual ele novamente remete a Benjamin quando o filósofo alemão destaca que o capitalismo é a religião atual, ou seja, o poder econômico é o deus que rege as vidas inclusive tendo sobre elas um poder de vida e de morte (AGAMBEN, 2012), responde a essa questão:

Para entendermos o que está acontecendo, é preciso tomar ao pé da letra a idéia de Walter Benjamin, segundo o qual o capitalismo é, realmente, uma religião, e a mais feroz, implacável e irracional religião que jamais existiu, porque não conhece nem redenção nem trégua. Ela celebra um culto ininterrupto cuja liturgia é o trabalho e cujo objeto é o dinheiro. Deus não morreu, ele se tornou Dinheiro. O Banco - com os seus cinzentos funcionários e especialistas - assumiu o lugar da Igreja e dos seus padres e, governando o crédito (até mesmo o crédito dos Estados, que docilmente abdicaram de sua soberania), manipula e gere a fé - a escassa, incerta confiança - que o nosso tempo ainda traz consigo. Além disso, o fato de o capitalismo ser hoje uma religião, nada o mostra melhor do que o titulo de um grande jornal nacional (italiano) de alguns dias atrás: "salvar o euro a qualquer preço". Isso mesmo, "salvar" é um termo religioso, mas o que significa "a qualquer preço"? Até ao preço de "sacrificar" vidas humanas? Só numa perspectiva religiosa (ou melhor, pseudo-religiosa) podem ser feitas afirmações tão evidentemente absurdas e desumanas.

Tal citação, que tem como pano de fundo a política italiana, mas, assemelha-se a vigente situação do Estado brasileiro, no qual, a população precisa a qualquer preço fazer sacrifícios para "salvar" a situação econômica do país. Não é incoerente afirmar que neste contexto, vidas humanas são literalmente sacrificadas, tudo isto para salvar o deus, a religião do momento- o mercado. Há ainda outro agravante neste jogo que é impessoalidade, desse novo Leviatã que não é um soberano pessoal, com quem se pode confrontar diretamente, não é o ditador nazista de onde se sabia a origem sobre a ordem do controle sobre as vidas. O ser humano atual que não se delimita sobre a égide do mercado está fadado à morte. O mercado não tem rosto, é fugidio. É lógico que tem os seus gerentes, mas estes são difíceis encontrar, pois se escondem por detrás de números e estatísticas que são naturalmente frios e indiferentes a vida real, ao "chão 
da existência".

A vida sacra, se não tem mais valor, pode e deve ser eliminada. Esta reflexão pode estar associada ao utilitarismo, a frenética necessidade de produção atual. A vida que está fora da possibilidade de produzir riquezas ou movimentar de algum modo a máquina do mercado pode ser eliminada. "A vida nua não está mais confinada a um lugar particular ou em uma categoria definida, mas habita o corpo biológico de cada ser vivente" (AGAMBEN, p.146). Torna-se quase uma obrigação o corpo estar saudável, atuando, trabalhando, fazendo a economia fluir.

É difícil estabelecer uma política inclusiva, ou vital, na qual todas as pessoas participem da festa da existência não como coadjuvantes, mas como atores principais; são muitos os interesses que estão em jogo, se as sociedades lutarem para se tornarem mais humanas. Mas é cada vez mais urgente repensarmos as bases da política ocidental, antes que o colapso vigente se torne irreversível. Sempre existiu um espaço para que a vida nua fosse manipulada o que exige a emergência de uma política que já nasça vital e não mortal, na qual a soberania seja a própria vida.

Uma contradição fundamental a ser avaliada em um estado de exceção é uma vida viva, mas que subsiste como morta, ou seja, para muitos indivíduos a sua existência se reduz a qoé, pois as outras dimensões da existência estão na completa indignidade. A pobreza, a miséria e outras situações deploráveis não são apenas uma produção necessária para que o capitalismo subsista, é mais que isso, é força psicológica que impõe, sem fazer esforço, como se fosse um reality show, aos indivíduos a olharem e dizerem para si mesmos: eu não quero esta situação! E para fugir desse horror nos abnegamos a uma vida controlada pelo tempo e pelo labor, pela mera sobrevivência. Mas isto esconde a verdade de que o mundo não deveria ter donos e fronteiras, pois ambas são invenções que se tornaram verdades quase absolutas. Como afirma Agamben, "o trabalho é a liturgia" que mantém viva a fé no deus dinheiro, com o agravante de que este Leviatã ignora as vidas, ele precisa apenas subsistir, não importa a qual o curso!

O presente artigo visou abordar a política sob a perspectiva da vida. Partimos do princípio que a maioria maciça das organizações político-jurídicas no mundo ocidental fracassou ao dissociar vida e política ou de associar os dois termos de forma inadequada. Subvertendo o significado nobre da política que é fortalecer e possibilitar uma existência digna para os humanos.

Há um grande esforço de esconder sobre conceitos econômicos, administrativos, estatísticos, entre outros aspectos, a experiência objetiva dos indivíduos e grupos sociais, causando um distanciamento prático daquilo que seria o fundamental- viver com a máxima potência possível. Buscando leituras que estabelecem um vínculo estrito entre vida e política. Abordamos as teses do filósofo Giorgio Agamben sobre o conceito de vida nua. A partir dele, vislumbramos refletir sobre uma concepção de política que estabelece como prioridade os seres humanos reais e concretos. Entendemos que é a principal função da atividade política defender a vida, mas ela tem servido, conforme análise do filósofo alvo de nossa investigação, como um efeito colateral, servindo de instrumento de morte, de espaços nos quais vidas são matáveis. Tornar a política objeto de existências edificantes parece ser a tarefa da análise do pensador em questão. Pode parecer discurso escatológico, mas é urgentíssimo, pormos em debate tais questões sobre a inadequada proximidade entre vida e política visando soluções, encaminhamentos concretos- a favor da vida. É necessário pararmos e admitirmos: estamos no caminho errado! O modelo de política que predomina é predador de vidas, não intensificador delas! 


\section{Referências}

AGAMBEN, Giorgio. "Deus não morreu. ele tornou-se dinheiro". Revista IHU- Unisinos. Tradução de Selvino J. Assmann. Entrevista concedida a Peppe Salvà e publicada por Ragusa News, 16-082012. Disponivel em: http://www.ihu.unisinos.br/noticias/512966-giorgio-agamben. Acesso em 02 de setembro de 2017. 2004.

. Estado de exceção. Homo sacer II. Tradução de Iraci D, Poleti. São Paulo, Boi tempo,

. Homo sacer, o poder soberano e a vida nua, I. Tradução de Henrique Burigo. Belo Horizonte: Editora UFMG, 2007.

BARBOSA, Jonnefer Francisco. Formas e Políticas da Vida. In: Kínesis, vol. I, n 2. Marília: Unesp, 2009. Página 113.

BENJAMIN, Walter. Magia, técnica, arte e política: ensaios sobre literatura e história da cultura. Tradução Sérgio Paulo Rouanet, 8. ed. São Paulo: Brasiliense, 2012.

CASTRO, Edgardo Introdução a Giorgio Agamben: uma arqueologia da potência. Tradução Beatriz de Almeida Magalhães. Belo Horizonte: Autêntica Editora, 2012.

Duarte, André. 0 pensamento à sombra da ruptura: política e filosofia em Hannah Arendt. São Paulo, Paz e Terra, 2000.

Vidas em Risco: crítica do presente em Heidegger, Arendt e Foucault. Rio de Janeiro : Forense Universitária, 2010, p. 284.

Instituto Brasileiro de Pesquisas Aplicadas (IPEA). Atlas da Violência 2017 - Ipea e FBSP. Daniel CERQUEIR et AL.; Rio de Janeiro junho de 2017.

NETO PINTO, Moysés. A matriz oculta do Direito Moderno: crítica do constitucionalismo contemporâneo. Cadernos de ética e filosofia política, São Paulo, n. 17, p. 131-152, jan./jun. 2010.

SCHMITTI, C. Teologia Política. Belo Horizonte: Del Rey, 2006.

Artigo recebido em: 30 de outubro de 2019

Artigo aceito em: 31 de dezembro de 2019 